Article

\title{
A Study on the Development of Cranial Traction therapy Program for Facial Non-symmertric Correction -Utilize Delphi technique
}

\author{
Sung-Yeon Park ${ }^{1}$, Hea-Ju Hwang ${ }^{2 *}$ Kyu-Nam Park ${ }^{3 *}$ \\ 1,2 Graduate School of Medicine, CHA University, Seongnam-si, Gyeonggi-do 13503, Korea \\ 3 Graduate School of Public Health Industry, CHA University, Seongnam-si, Gyeonggi-do 13503, Korea \\ * Correspondence: imheaju@cha.ac.kr (H.-J.H.); km6160@naver.com (K.-N.P.)
}

\begin{abstract}
The purpose of this study is to develop a cranial traction therapy program to help correct facial asymmetry of the hard tissues through the means of the treatment of soft tissues - a non-surgical therapeutic method for the correcting of facial asymmetry. We have formed a group of experts who have agreed to the study. In the primary survey, open questions were used. In the second survey, the results of the first survey were summarized and the degree of agreement was presented to the questions in each category. In the third survey, we conducted a statistical analysis of the degree of agreement on each item of question. All surveys also performed email. The distribution was calculated using the SPSS (ver.23.0) program, and the mean difference between the result and $X^{2}$ was calculated. The significance level was set to $p<.05$. Most of the questions attained a certain level of consensus by the experts (average of 4.0 or higher), it can be said that most are important and suitable questions. the results regarding the degree of importance for each of the points of evaluation made by the groups of experts in both the second and third stage of the cranial traction therapy program were verified using content validity ratio (CVR 77). The ratio for the cranial traction 13 points of evaluation was within the range of 0.40 1.00 , so the Delphi program for the cranial traction therapy verified that the content was valid.
\end{abstract}

Keywords: Cranial Traction Therapy. Correcting Facial Asymmerty

\section{Introduction}

In modern society, regardless of age or gender, everyone strives to put his or her efforts into self-management. Beauty and outer appearance are deemed important for individuals who have interest in appearance.

Lookism is a term used to refer to appearance consciousness; it considers appearance as the highest standard. This term started from the United States. It is one of the newer words that have been added to the long list of types of discrimination or prejudice against people, such as those based on their race, gender, religion, and ideology.

In particular, it is becoming harder to determine who is qualified and who is not, as competition intensifies in the modern society; so the elements of discrimination that are more obvious and easy to perceive are becoming one of the more important evaluation criteria. As such, aesthetic plastic surgery has been attracting more and more people[1]. 
In the past, it was mainly women who cared for their beauty,but men nowadays are also trying to create a neat and clean image for themselves.

The beauty trend is one dominated by small and slim faces reduced in size with neat and healthy skin. The biggest cause of facial asymmetry due tolifestyle is excessively formed masticatory muscle[2]. In addition, there are other elements like facial swelling, double chin, excessive fat, inconspicuous facial contours, dropping down cheeks and sagging jaw lines[3].

Facial asymmetry could be a reason for the forming negative images and the lowering of self-esteem in interpersonal relationships[4]. Thus, symmetry and balance of the facial parts are very critical. Recently, the CFRT craniofacial surgery has been introduced as a surgical operation without any intervention from dental and medical treatment,but its side effect after surgery and heavy expenses make it uneasy to access in daily life.

Various congenital or acquired factors like unilateral mandibular, hemi-facial macrosomia, mandibular condyle fractures and condylar ankyloses can cause facial asymmetry[5]. It is well known that mandibular symphysis ectopic is greatly influential in recognizing facial asymmetry[6]. Habits repeated during one's life result in the forming of an unbalanced or distorted face shape with asymmetry on both sides or front and rear parts of a face. Particularly, turtle neck, spinal scoliosis, and pelvic slop heavily affects body imbalance. When the balance of a human body is broken, it is difficult to restore it by itself; and symptoms will continue to get worse.

Symptoms of such facial asymmetry can lead to temporomandibular joint disorders like temporomandibular joint pain-and articulation and trismus disorders,and may present ophthalmodynia, cephalalgia, a painful neck, and leg length imbalance. Nevertheless, people with facial asymmetry do not easily recognize the changes in their faces and its seriousness.

Facial asymmetry refers to an incomplete match in size, location, and shape of bilateral structures in relation to the centerline,and most people have this asymmetry[7] The number of patients visiting a clinic due to facial asymmetry-is increasing.In the past, this asymmetry was referred to as one of the morphological characteristics of the body. Park Jeong-Shin's "Evaluation of the Facial Soft Tissue in the Frontal View After Surgical Correction of Facial Asymmetry"'[8] reported that features of facial asymmetry are found with even normal people [9-14], and thus a more systematic and accurate approach to facial asymmetry became necessary.

The assessment on soft and hard tissues of the frontal face is critical and essential in order to diagnose, predict,and make an evaluation of the results from facial asymmetry treatment[8]. Although facial asymmetry is diagnosed through quantitative evaluation of hard tissue, it is recognized not only by the asymmetry of the hard tissue but also by that of the soft tissue[15].

In Yogosawa's "Predicting Soft Tissue Profile Changes Concurrent with Orthodontic Treatment"[16], it wassuggested that skeletal abnormalities can be covered by soft tissues such as muscles and skin. Lee Dae Jeong's "Comparison of Asymmetric Degree Between Maxillofacial Hard and Soft Tissue in Facial Asymmetric Subjects"[17] and "Skeletal Asym-metry in Esthetically Pleasing Faces" by Peck et al[10]. reported that people with symmetrical facial features still have skeletal asymmetry, and proved that there is a difference in the degree of asymmetry between hard and soft tissues. Park Hee Keun's "Three-dimensional Assessment of Correlation Between Lip Caning and Craniofacial Planes"[18], "Craniofacila Morphometry by Photographic Evaluations" by Ferrario et al[19], and "Facial Asymmetry in Subjects with Skeletal Class III Deformity" by Haraguchi et al[20]. All identified that there is also a difference in the degree of the role that 
asymmetry between the hard and soft tissues play when it comes to recognizing Class III asymmetry of the craniofacial skeleton[17].

The cranial grows up to over $90 \%$ of the adult size by the age of $5-7 ;$; and the facial bones grow in an anterior-posterior direction before the age of 3 and in a posterior direction after the age of 3 . At the age of 8 , it changes from horizontal to vertical growth. Hereafter, as one ages, it grows in various types and directions, depending on the time and area,with different proportions of the facial and cranial parts in the head $[21,22]$.

A normal growth-results inthe ratio between the face and the cranium being even, achieving a harmonious appearance even if the left and the right may not be identical. However, in some severe cases, the harmony and balance of the face and the cranium canbe broken with a malfunction resultingfrom a defect in the normal process or an abnormal development during formation and growth[23].

Cranial traction treatment is a therapeutic method in which the suture surfaces that touch each other-are pushed or pulled, keeping in mindthe fact that the craniofacial skeleton has its own movements. It increases each of the movements of the craniofacial skeleton and changes the frame of the otherwise limited cranial and facial bones [24]. It is-therapy that applies adequate time and intensity to effect changes in the skeleton by the direction of the unique movements of the cranial and facial bones to treat facial asymmetry, according to the principle of craniosacral therapy in John E. Upledger's Craniosacral Therapy[25].

In particular, since the movements of the cranium bones affect the facial bones, suturing the cranial plays an important anatomical role in correcting facial asymmetry[26]. In Kim Kyung-Suk's "Cranial Base Shape According to Skeletal Maloccusion and Effect of Ceania Base on Maxilla and Mandible"[27], it was stated that as the angle of base of the cranial increases, the condylion's position shifts toward the posterior upper part. By looking atthe resulting movement of the mandible rotating posteriorly and upward, one can predict that the change in the cranium bones forming the base of the cranial will be revealed to have beenrelated to facial asymmetry.

Park So Jeong's "Study on Patients with Facial Asymmetry According to the Skeletal Pattern"[28] presented that facial asymmetry is indicated by differences in the vertical length of the left and right structures or in the horizontal width of the midline. However, the result of classifying by skeletal shape type revealed that the differences in types have some level of significance. She saw that theskeletal shape could appear differently depending on the motion limitation of the cranial or facial bones, so in her study, shetried to examine whether the skeletal shape would measure differently after improving the limitations in themovements of each bone.

In addition, Lee Dae-Jeong's “Comparison of Asymmetric Degree Between Maxillofacial Hard and Soft Tissue in Facial Asymmetric Subjects"[17] suggested that a difference in the degree of asymmetry between soft and hard tissues was seen in patients with facial asymmetry, indicating that an analysis of asymmetry using the soft tissues measurement items would be necessary along with that of the hard tissues for evaluation of facial asymmetry.

In the field of skin care and cosmetology, a wide range of studies on facial reduction were looked intowith various methods like the meridian massage, the tibia massage, miso facial acupuncture, skeletal muscle therapy,and electrical nerve stimulation through Yu Eun-Ju's "A Study of Effect on Face Reduction and Physiological Factor of College Women by Nerve Stimulation Therapy”[29], Kwon Gi Sun's “The Effect of Miso Facial Acupuncture on Facial Reduction and Improvement of Skin Condition'[30], Kwon Kyoung Ja’s 
"The Effects of Golgeun Therapy on Facial Size Changes for Men in Their 20s and 30s"[31], We Soo-Young's "The Effect of Golgeun Therapy on Facial Volume, Thickness of Cheekbone and Mastication Area"[3], Byeon In-Hee's "Effect of Kyunggol Massage on Facial Reduction"[32]. However, there has never been a study evaluating facial asymmetry through either the soft or the hard tissues [33].

Therefore, it is fit that an effective facial correction method be designed to reduce the burden of side effects, as well as to save time and the cost for cosmetic surgery and treatment through a relatively simple procedure. This paper proposes for a scientific and systematic program to be developed using point-by-point stimulation manual therapy on the cranial bone suture surface - a method which is currently being used in orthopedics, oriental clinics, and therapy shops.

The purpose of this study is to develop a cranial traction therapy program to help correct facial asymmetry of thehard tissues through the means of the treatment of soft tissues - a non-surgical therapeutic method for the correcting of facial asymmetry..

\section{Method}

\subsection{Ethical approval}

The study was approved by the ethtics committee of the CHA University (1044308-201911-HR-082-03/ 20200414). The applied protocols align with the Declaration of Helsinki. All participants signs an informed consent form.

\subsection{Subject of Study}

The purpose of this study is to develop a cranial traction therapy program for correcting facial asymmetry by conducting a study that takes into account the opinions-of various experts. Accordingly, the suitable method of choice was the Delphi technique, so that content validity for the development of the cranial traction therapy program can be verified.

When it comes to the Delphi technique, the selection of subjects is very critical to the success of the study. The panel of experts chosen was as follows; rehabilitation medical specialists (2), oriental medicine doctors (2), dentistry specialists (2), educators in the field of skin care that was in accordance with the higher education act (4), and master's or doctoral degree holders in skin care and cosmetology with more than 10-years of experience in the field (5). These experts were selected based on whether they had made previous presentations on the topic of cranial traction therapy or for their career experiences in their respective positions as researchers in their institutes.

Table 1. Expert Panel Composition

\begin{tabular}{lccc}
\hline Group & The First & The Second & The Third \\
\hline $\begin{array}{l}\text { The panel of experts(Rehabilitation medical specialists, oriental } \\
\text { medicine doctors, dentistry specialists) }\end{array}$ & 6 & 6 & 6 \\
\hline master's or doctoral degree holders in skin care and & 5 & 5 \\
cosmetology with more than 10-years of experience in the & & & 5 \\
\end{tabular}


field

\begin{tabular}{rlcc}
\hline educators in the field of skin care & 4 & 4 & 4 \\
\hline Total & 15 & 15 & 15 \\
\hline
\end{tabular}

Table 1. presents the number of subjects who participated in the survey over the three stages. The number of survey participants started with the first 15 people, a number that was picked based on theories in the book by Adler \& Ziglio-titled Gazing into the Oracle: The Delphi technique and Its Application to Social Policy and Public Health[34], as well as those in the book by Giannarou and Zervas titled Using Delphi Technique to Build Consensus in Practice[35]. This final group of 15 people participated in the third stage. In order to meet the targeted amountof opinions to collect during the second and third stages, the studywas necessarily conducted up to the third stage. It was verified that there were no experts left out in the contribution of their opinions in all three stages. The first survey began in June 2020, and the final third survey was completed on July 30, 2020.

\subsection{Delphi survey tools}

The Delphi technique is a method that allows for systematically inducing and contrasting perceived judgments on a specific subject[36]. What comes first in the process is the selection of experts in the relevant field. In order to increase the validity and credibility of the Delphi results, the following characteristics of the experts must be considered: their representativeness, relevance, expertise, integrity of participation, and adequacy in number $[34,35]$. Based on this theory, 15 experts were selected to take part inthe Delphi survey.

The number of experts to be selected for the panel can vary to meet the needs and size of the study, but a sample group of at least 10 people must formed-in order for errorsin the mean values to be minimized and for the study to be credible.In general, samples numbering between 10 and 15 are accepted as valid in the Delphi survey [34, 37]. The Delphi technique analyzes and synthesizes the responses given by the group of experts systematically to predict, diagnose, and solve certain problems until the goal of group consensus-is achieved.

\subsection{Selection of development tools}

The 14 items for cranial traction therapy, which was based on the concept of manual therapy dealing with cranial structures, were selected by William Sutherland, who was a student of Still, the founder of osteopathic medicine on the human brain in 1943. The principle of biomechanics of all the joints in the human body is a passive and active system of the joints that distributes forces to achieve the balance between movement and restriction, and is system of balance that controls the action of movements. The selection based on the active system included joints outside of those that bring about movements.

Table 2. Fourteen selected items according to the development test of the cranial traction therapy program

\begin{tabular}{llll}
\hline Traction Therapy Item & Question & Traction Therapy Item & Question \\
\hline
\end{tabular}




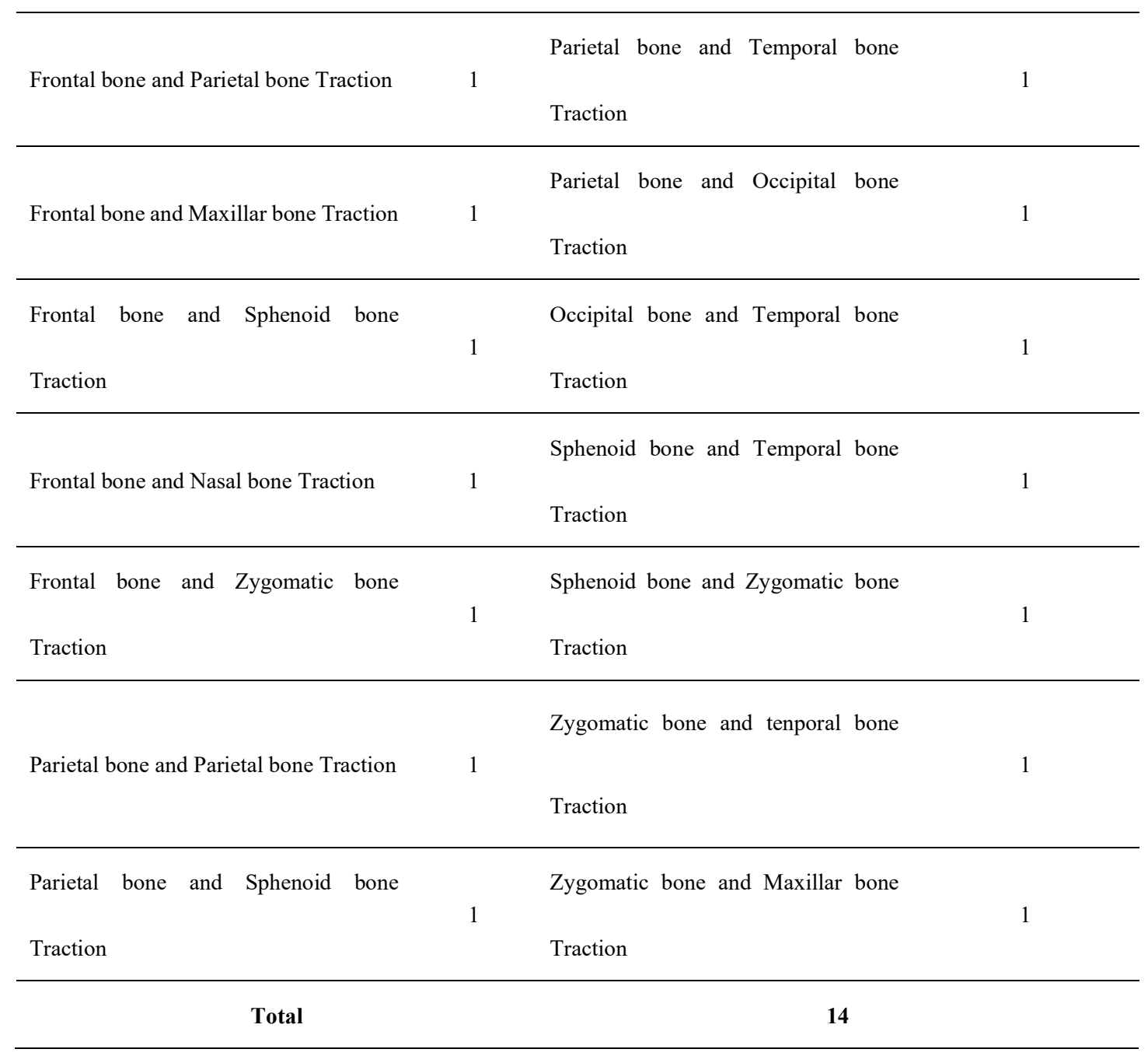

\subsection{Theoretical Background of Selected Development Tools}

Just like other joints in the human body, the joints of the cranial have movements that result from external as well as internal forces that bring about internal balance. Some of the typical features of the structure of the joints include maintaining of its structure by the fixation of the restorative ligaments, free nerve terminal, veins and arteries, proprioceptors in sutures like the slippery side, superior periosteum, falx cerebri, and the tentorium cerebri [38].

First, the biomechanics of the cranial motion is possible with the combination of the plasticity of the bones, so minute movements are possible with the anterior and posterior axes of the horizontal and vertical axes. Occipital bone, sphenoid bone, frontal bone, ethmoid bone, and the vomer bone mostly have movements of flexion and extension. The movements of the temporal bone, the parietal bone, the palatine bone, and the zygomatic bone are made up of external and internal rotations[25].

The general movement of the cranial system is a cyclic movement in the active and passive stages-active stage is a combination of external rotations which results from the flexion and expansion-of the ossa centrale.The 
passive stage is a combination of internal rotations which result from the extension of the ossa centrale and the relaxation of the surrounding bones. Each bone shows a specific movement along the three axes [38]. The movement of occipital bone is caused by bending and extending around the horizontal axis located at the intersection of the two sides that pass the anterior boundary of greater occipital bone and upper boundary of occipital bone.

The movement of the sphenoid bone occurs downward and forward with respect to the central axis located at the center of the sphenoid bone by the greater wing of the sphenoid bone and the movement on horizontal axis passing through the sphenoid bone rostrum. The movement of the anterior forehead bone moves the posterior and upper boundary of the anterior forehead bone posteriorly and downward around the central axis, and the eyebrow bow moves forward and upward.

The movement of the temporal bone has three axes of rotation-the petro-basilar pivot that meets the occipital bone and the sphenoid bone-;spheno-petrous pivot, and the petro-jugular pivot which meets the occipital and sphenoid bone. The petro-basilar pivot slides so that the cranial can be expanded, and the petro-jugular pivot causes an outer rotation of the horizontal axis and a counterclockwise rotation of the vertical axis.

The sphenoid-petrous pivot has rotation around the clinoid process insertion point of the petro-sphenoid bone ligament.

The movement of the parietal bone occurs where the coronal suture meets the frontal bone and squamous suture meeting the temporal bone, with lambdoid suture meeting the occipital bone with outer rotational movement that bendssimultaneously. The outer part of the coronal suture moves forward and is everted. The inner part of the coronal suture and the depressed bregma moves posteriorly. The sagittal suture surface is depressed with the border of the parietal bone-and moves posteriorly.

Lambdoid suture gets depressed and the lambdoid suture surface of the posterior head boundary moves backward. Squamous suture surface gets depressed and the outer part of the parietal bone moves forward and gets ectropion [39].

Second, the movement of the facial bone transfers movement to all the bones that make up the maxillar bone and joints by delivering movement of sphenoid bone, temporal bone, and frontal bone to the maxillar bone [40].

The movement of the maxilla is the inner and outer rotational motion of the maxillar bone, where the upper part passes through the front of the maxillar bone,and the lower part moves at the slanted axis passing through the anterior lateral angle. While sphenoid bone is bent, the maxillar bone moves posteriorly as the suture between the maxillar bones is lowered and each maxillar bone moves backwards. The posterior boundary of the frontal bone is raised and the anterior surface moves anterior-laterally.

The movement of the zygomatic bone forms the joints with the maxillar bone, frontal bone and temporal bone, and rotates anterior-outward during bending, pulls the orbital boundary of the zygomatic bone towards the outside, letting the orbit widen, and the frontal bone protrusion moves to the anterior and lateral surfaces, and the temporal process of the zygomatic bone moves downward-outward [39]. 
In addition, through what was stated by Ferrario et al. in "Craniofacila Morphometry by Photographic Evaluation"[19] and Haraguchi et al. in "Facial Asymmetry in Subjects with Skeletal Class III Deformity" [20] the 14 items of cranial traction therapy were set as shown at Table 3, and the measurement on the surgical procedures and facial correction displacement for 14 items in of cranial bone synaptic parts was performed, based on the evidence verifying that there is a difference in the degree of asymmetry between hard and soft tissues in the recognition of severe Class III craniofacial skeleton asymmetry.

Table3. Cranial dog therapy program (14 items)

\begin{tabular}{|c|c|c|}
\hline $\begin{array}{c}\text { Traction } \\
\text { Therapy Item }\end{array}$ & Tteatment Photograph & Item Description \\
\hline $\begin{array}{l}\text { 1. Frontal bone } \\
\text { and Parietal } \\
\text { bone Traction } \\
\text { (Both Sides) }\end{array}$ & & $\begin{array}{l}\text { Therapist: supine position } \\
\text { Hand position: From the center of the edge of the } \\
\text { head, go up three finger breadths, and move and } \\
\text { fix the thumbs at } 1 \mathrm{~cm} \text { 's distance towards the front } \\
\text { and the back of the line, one on the parietal bone } \\
\text { side of the coronal suture and the other on the } \\
\text { frontal side. } \\
\text { Method: For the thumb on the frontal bone, } \\
\text { exerting strength against the resisting periosteum, } \\
\text { perform traction away from the thumb fixed on } \\
\text { the parietal bone in the directions indicated by the } \\
\text { arrows ( } 3 \text { point). }\end{array}$ \\
\hline $\begin{array}{l}\text { 2. Frontal bone } \\
\text { and Maxillar } \\
\text { bone Traction } \\
\text { (Both Sides) }\end{array}$ & & $\begin{array}{l}\text { Therapist: supine position } \\
\text { Hand position: Fix one hand on the superciliary } \\
\text { arch that is on the inside of the frontal bone, and } \\
\text { fix the other hand on the frontal process of the } \\
\text { maxilla. } \\
\text { Method: With the middle finger fixed on the } \\
\text { superciliary arch that is on the inside of the frontal } \\
\text { bone, and with the maxilla fixed in place by the } \\
\text { other thumb, exerting strength against the } \\
\text { resisting periosteum, perform traction in opposite } \\
\text { directions indicated by the arrows ( } 1 \text { point). }\end{array}$ \\
\hline
\end{tabular}


Therapist: lateral position

Hand position: Drawing a line from the end of the eyebrow to the edge of the head, fix the thumbs on the outside and the inside of the middle point of that line.

Method: At the middle point of the line, exert strength against the resisting periosteum using both thumbs and perform traction in the directions indicated by the arrows ( 1 point).

4. Frontal bone and Nasal bone Traction

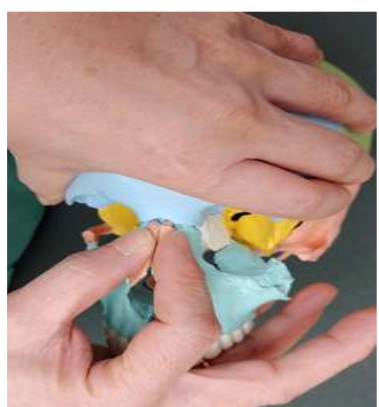

Therapist: supine position

Hand position: Fix the thumb and the fingers on the frontal bones, while fixing the thumb and the index finger of the other hand on the nasal bone.

Method: Perform traction towards the back with the palm that is fixed on both sides of the frontal bone, and when exhaling, perform downward traction of the nasal bone, exerting strength against the resisting periosteum (1 point).
Traction

\section{Therapy Item}

5. Frontal bone and Zygomatic bone Traction (Both Sides)

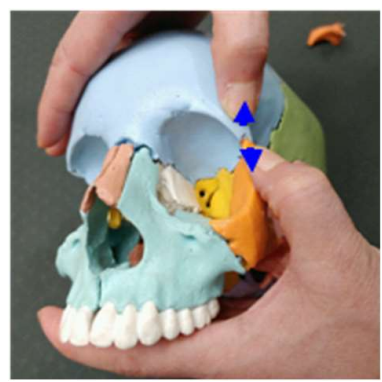

Therapist: supine position

Hand position: Fix both thumbs at the recess that is at the zygomatic process of the frontal bone above the lateral canthus.

Method: Perform traction with the thumbs in the directions indicated by the arrows, exerting strength against the resisting periosteum (1 point). 
6. Parietal bone and Parietal bone Traction

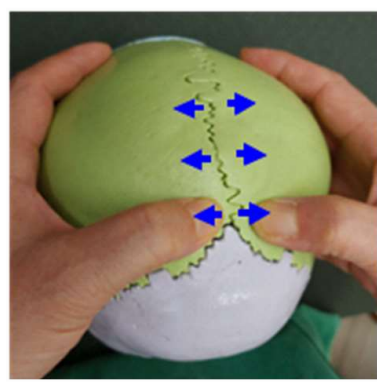

7. Parietal bone and Sphenoid bone Traction (Both Sides)

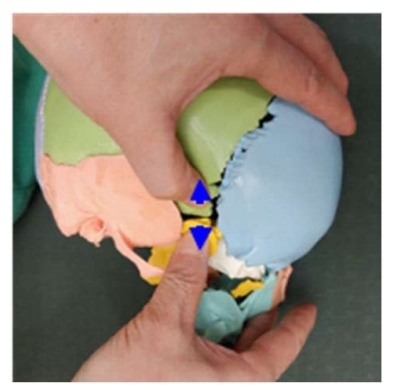

8. Parietal bone and Temporal bone Traction (Both Sides)

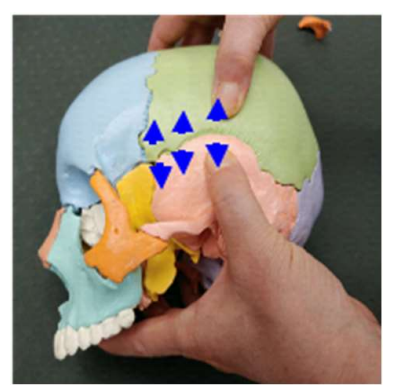

Therapist: prone position

Hand position: Fix each of the thumbs at points marked by one finger breadth distance front and back from the center of the line that connects the two ears.

Method: Perform traction with both thumbs from the middle point of the head towards the directions indicated by the arrows, exerting strength against the resisting periosteum (3 points).

Therapist: lateral position

Hand position: Drawing a line from the lateral canthus to the edge of the head that is parallel to the line connecting the end of the eyebrow to the edge of the head, fix both thumbs at the middle point of that line.

Method: Fixing both thumbs at the middle point of the line connecting the lateral canthus to the edge of the head, perform traction in the directions indicated by the arrows, exerting strength against the resisting periosteum (1 point).

Therapist:lateral position

Hand position: Find the point where the horizontal line drawn from the end of the eyebrow meets the vertical line drawn from the top of the ear, and fix each of the thumbs at points marked by one finger breadth distance front and back from that point.

Method: Perform traction with the thumbs in the directions indicated by the arrows, exerting strength against the resisting periosteum (3 point). 


$\begin{array}{lll}\text { Traction } & \text { Tteatment Photograph } & \text { Item Description } \\ \text { Therapy Item } & \end{array}$

9. Parietal bone
$\begin{aligned} & \text { Therapist: prone position } \\ & \text { Traction }\end{aligned}$
(Both Sides)

$\begin{array}{ll}\text { 10. Occipital bone } & \text { Therapist: prone position } \\ \text { and Temporal } & \begin{array}{l}\text { Hand position: Fix both thumbs at the recess that } \\ \text { is at the back of the mastoid. }\end{array} \\ \text { bone Traction } & \text { Method: Perform traction with the thumbs in the } \\ \text { (Both Sides) } & \begin{array}{l}\text { directions indicated by the arrows, exerting } \\ \text { strength against the resisting periosteum (1 }\end{array}\end{array}$

Therapist: lateral position

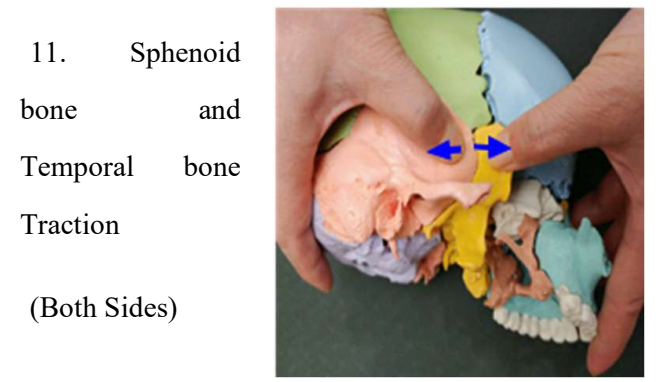

Hand position:Fix both thumbs at the middle point of the sideburns line above the temporal process.

Method: Perform traction with the thumbs in the directions indicated by the arrows, exerting strength against the resisting periosteum (1 point).

\section{Therapist: lateral position}

12. Sphenoid bone and Zygomatic bone Traction (Both Sides)

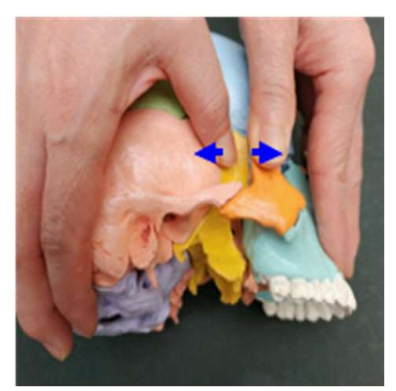

Hand position:Following the horizontal line drawn from the lateral canthus, fix one thumb at the zygomatic bone and the other at the recess behind it.

Method: Perform traction with the thumbs in the directions indicated by the arrows, exerting 
strength against the resisting periosteum (1

point).

\subsection{Research procedure}

In the first stage, evaluation papers about cranial traction therapy were given, and an example of said therapy was presented, so as to hint towards the correct answers for this test. The evaluation paper included both open-ended and close-ended questions. The open ended questions were those regarding the duration application time, application frequency, and application intensity. For close-end questions, they were those regarding the 14 items on cranial traction therapy. As shown in Table 3, 14 questions were made through the analyzing the contents from the first survey. To make sure to have reliability in the conducting of this analysis, the content analysis of the survey was done by experts. The three people involved here were a rehabilitation medical specialist, a doctor of a Chinese medical college, and a professor from the department of skin care and cosmetology. They each organized the results that were related to their respective fields. Then, the those results were again looked over by 5 members, who discussed the disagreements that had occurred; in this way, the final set of questions were selected.

As a result of the analysis of the first open-ended questions, a total of 14 items for the cranial traction therapy program for the correction of facial asymmetry-were selected. The second set of questions included ones that were made through content analysis of the first open-ended questions; then they were finalized using Likert's five point scale. Each item was chosen as one of the following categories: 5 points for "very suitable", 4 points for "somewhat appropriate", 3 points for "normal", 2 points for "slightly unsuitable", and 1 point for "very unsuitable". The mean and standard deviation of items for cranial traction treatment program development for facial asymmetry correction were thus acquired.

In the result of the first survey, out of the 14 items, the level of consensus (average 4.0 or higher) of experts was low with the fourth items regarding the frontal and nasal bone traction question. This question was deleted and then the second and third survey were carried out with 13 question items. The third survey consisted of the same questions as that of the second stage, except they were marked with the results from the second survey: the opinions of each individual, along with the average of each question. Consequently, As shown in Table 4, 13 questions in total were developed and the result from the second and third surveys revealed that all of them there was a high level of consensus (average 4.0 or higher) among the experts. The study on the cranial traction therapy program for facial asymmetry correction was thus developed, consisting of a total of 13 items.

1) The papers evaluating the 14 items included open-ended question survey items that were related to the development of the program. They included duration of application., application frequency, and intensity of application. They also included close-ended question survey items, which were related to the 14 items of the 
cranial traction therapy. The observation items were related the verification of the validity of this study by the three experts: the medical rehabilitation specialist, a doctor from a Chinese medical college, and a professor of skin care and cosmetology. In this way, the duration application time, application frequency, application intensity, and the 14 items of the cranial traction therapy were selected.

2) 15 members were chosen to be the panel of experts for the Delphi survey.

3) First survey: both open-ended and close-ended question surveys were conducted. The duration application time, application frequency, and application intensity were chosen as the open-ended question items, while the 14 items of cranial traction therapy were chosen for the close-ended questions.

4) 2st survey: this survey was focused around close-ended questions. Previously gathered information about the duration application time, application frequency, and application intensity were analyzed as a whole to create standardized close-ended questions, and thus the program was established. In regards to the 13 items of cranial traction therapy, the Likert five point scale was used to analyze and compress the ideas collected, and according to the questions of each category, items about which a certain level of consensus (average of 4.00 or higher) were reached were selected.

5) 3st survey: the close-ended question survey of this third round were made based on the opinions of the panel of experts collected in the second survey. Through a statistical analysis of the answers for this survey, the final consensus of the panel of experts was reached.

In this study, the items for traction therapy which was conducted in the order as according to the designated numbers of each cranial suture were classified as according to Table 4, and the number of the treatment points for the traction therapy were from 1 to 3 , and the processes of change of the parts were converted into data, keeping that of each of the treatment points separate.

Table 4. Treatment points according to 14 items of cranial traction therapy

\begin{tabular}{ccc}
\hline Separation & Traction Therapy Item & Item Point \\
\hline Coronal Suture & $1 . \quad$ Frontal bone and Parietal bone Traction & Both-sided procedure with three \\
& & points \\
\hline
\end{tabular}


Not applicable for cranial

suture 2. Frontal bone and Maxillar bone Traction

Both -sided procedure with one points

Spenofrontal Suture

3. Frontal bone and Sphenoid bone Traction

Both -sided procedure with one points

4. Frontal bone and Nasal bone Traction

Not applicable for cranial suture
\#4 was deleted as a result of the

opinions gathered from the experts during

the 1 st survey.
5. Frontal bone and Zygomatic bone

Not applicable for cranial suture
Traction
One points procedure

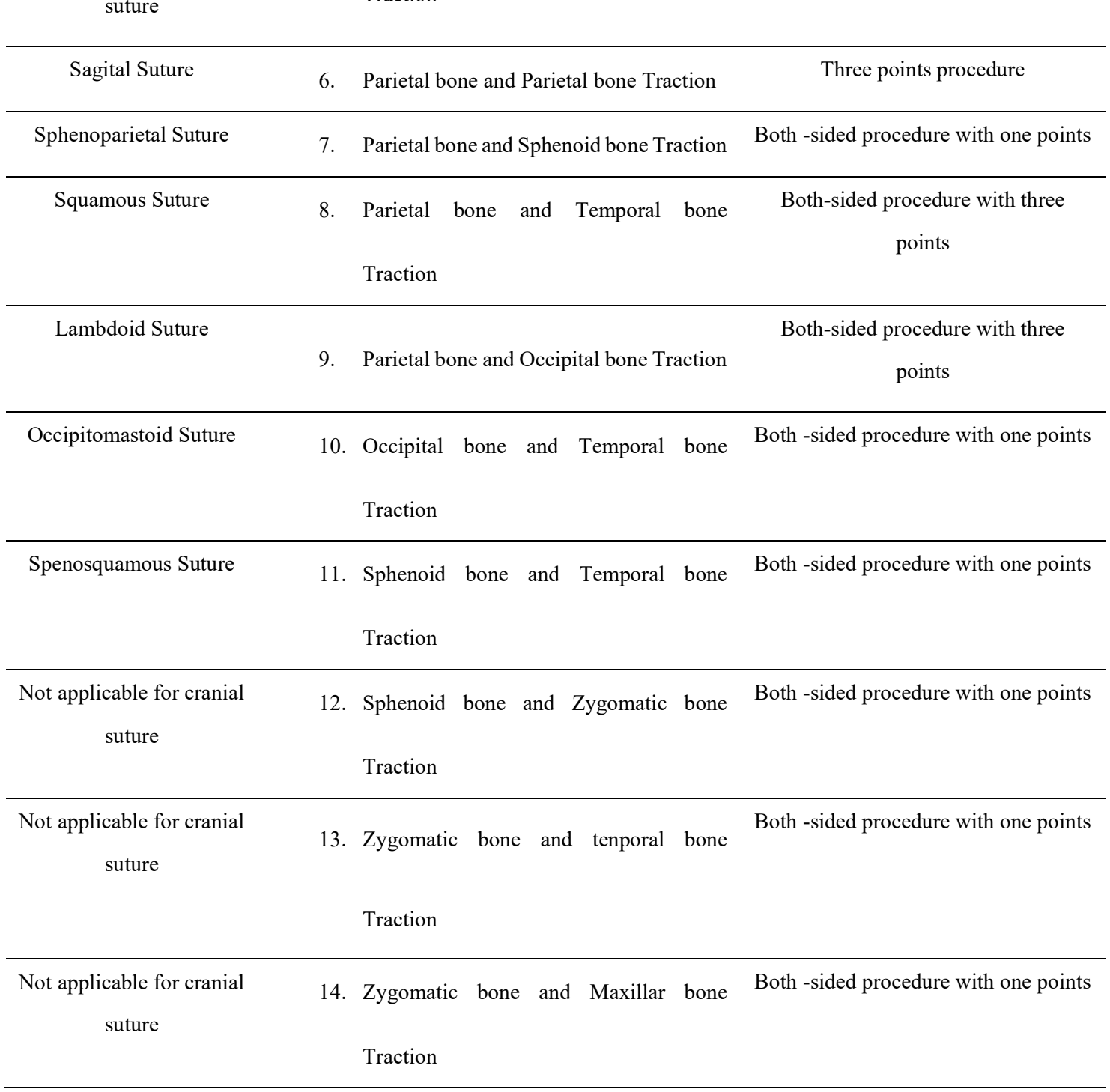




\section{7. processing data and Statistical analysis}

There were a total of three surveys in this study. Prior telephone or face-to-face contact was made in order to present the study's purpose. The experts who agreed with the study were selected here. In the first survey, open-ended questions were used. For the second survey, the results of the first survey were organized and the degree of consensus for questions of each category were presented. This survey was done through email. For the third survey, a statistical analysis of the degree of consensus for the questions of each category was conducted. This survey was also done through email. The SPSS WIN 23.0 program will be used to apply the Delphi technique on the results of the second and third surveys, so that the following statistics can be calculated. Based on the consolidation of the responses from experts, the mean, the standard deviation, the median, and the interquartile range will be calculated. By allowing the comparison between the statistics of the entire group of experts and the statistics of the individuals' responses to take place, the opportunity to reconsider one's own opinions will be given. In addition, in order to determine the validity of each component, the content validity ratio, as well as the degree of consensus and convergence will be calculated. The CVR was calculated using the calculation formula made by Lawshe[41], Park Seon Yeong[42].

$$
\mathrm{CVR}=\frac{N_{2}-\frac{N}{2}}{\frac{N}{2}}
$$

$\left(\mathrm{N}=\right.$ number of responses, $N_{2}=$ the sum of the number of 'very important' and 'important' responses as according to the Likert scale)

The degree of consensus and convergence must be calculated to determine whether opinions collected from the panel of experts have reached a consensus point. To calculate this statistic, the median and quartile values are needed. Among the quartiles, the Q1 and Q3 represent values corresponding to the first quartile coefficient and the third quartile coefficient, $25 \%$ and $75 \%$. The following are the formulas to calculate the degree of consensus and convergence[43].

$$
\text { Consensus }=1-\frac{Q_{3}-Q_{1}}{M d n} \quad \text { Convergence }=\frac{Q_{3}-Q_{1}}{2}
$$


The statistical analyses of each stage will utilize the open-ended question survey and the papers of evaluation that used Likert's five point scale. The second survey was a survey using Likert's five point scale, based on the organized results from the first survey; the degree of consensus regarding questions for each category was presented using the second evaluation paper. The third survey will evaluate the degree of consensus for the questions of each category questions which will be made by utilizing the same methods as that of the second survey. The answers collected at each stage were be checked for any omissions, and were be entered into the computer one by one in the form of data which can be analyzed; then the frequencies program of SPSS (ver.23.0) was used to calculate the frequency distribution, and the average difference between the results, as well as their $\mathrm{X}^{2}$, were verified. The level of significance was set to $\mathrm{p}<.05$.

\section{Results}

A survey regarding the development of the cranial traction therapy program was conducted. The validity and the verification for the study's homogeneity (credibility), which were the points of evaluation for this study according to the survey results, were then analyzed through survey questions, which consisted of the three open-ended ones regarding the duration application time, application frequency, and application intensity, along with the close-ended ones which were made up of the aforementioned 14 items. The results of the development of the cranial traction therapy program for the correction of facial asymmetry can be seen in Table 5. \& Table 6 . The first survey was remained to 13 questions. The second survey's results for those 13 items are as follows: the mean value was above 4.60 - this being the highest value - for questions regarding the traction of the frontal bone and the maxilla, the traction of the frontal bone and the sphenoid bone, the traction of the sphenoid bone and the zygomatic bone, the traction of the zygomatic bone and the temporal bone, and the traction of the zygomatic bone and the maxilla. On the other hand, the mean value was 4.40 - this being the lowest value-for the question regarding the traction of the frontal bone and the parietal bone. The third survey results showed the mean value of 4.93 as the highest value for questions regarding the traction of the frontal bone and the sphenoid bone, the traction of the frontal bone and the zygomatic bone, the traction of the frontal bone and the parietal bone, the traction of the parietal bone and the sphenoid bone, the traction of the parietal bone and the temporal bone, the traction of the occipital bone and the temporal bone, the traction of the sphenoid bone and the temporal bone, the traction of the sphenoid bone and the zygomatic bone, the traction of the zygomatic bone and the temporal bone, and the traction of the zygomatic bone and the maxilla. On the other hand, the mean value was 4.87 - this being the lowest value - for questions regarding the traction of the frontal bone and the parietal bone, the traction of the frontal bone and the maxilla, and the traction of the parietal bone and the 
occipital bone. The difference between the mean values was highest for the third survey, at a value of 0.26 . The lowest difference was the difference between the second and third surveys, at a value of 0.47. However, since most of the questions attained a certain level of consensus by the experts (average of 4.0 or higher), it can be said that most are important and suitable questions. Also, as can be seen in Table 5, Table6, the results regarding the degree of importance for each of the points of evaluation made by the groups of experts in both the second and third stage of the cranial traction therapy program were verified using content validity ratio (CVR 77). The ratio for the 13 points of evaluation was within the range of $0.40 \sim 1.00$, so the Delphi program for the cranial traction therapy verified that the content was valid. As shown at Table 7 , the adopted results for questions that did not show adequate levels of significance $(\mathrm{p}<.05)$ by the verification of the homogeneity (credibility) are as follows.

Table 5. Analysis of the validity of the assessment factors of the results of the Cranial Traction Therapy Program

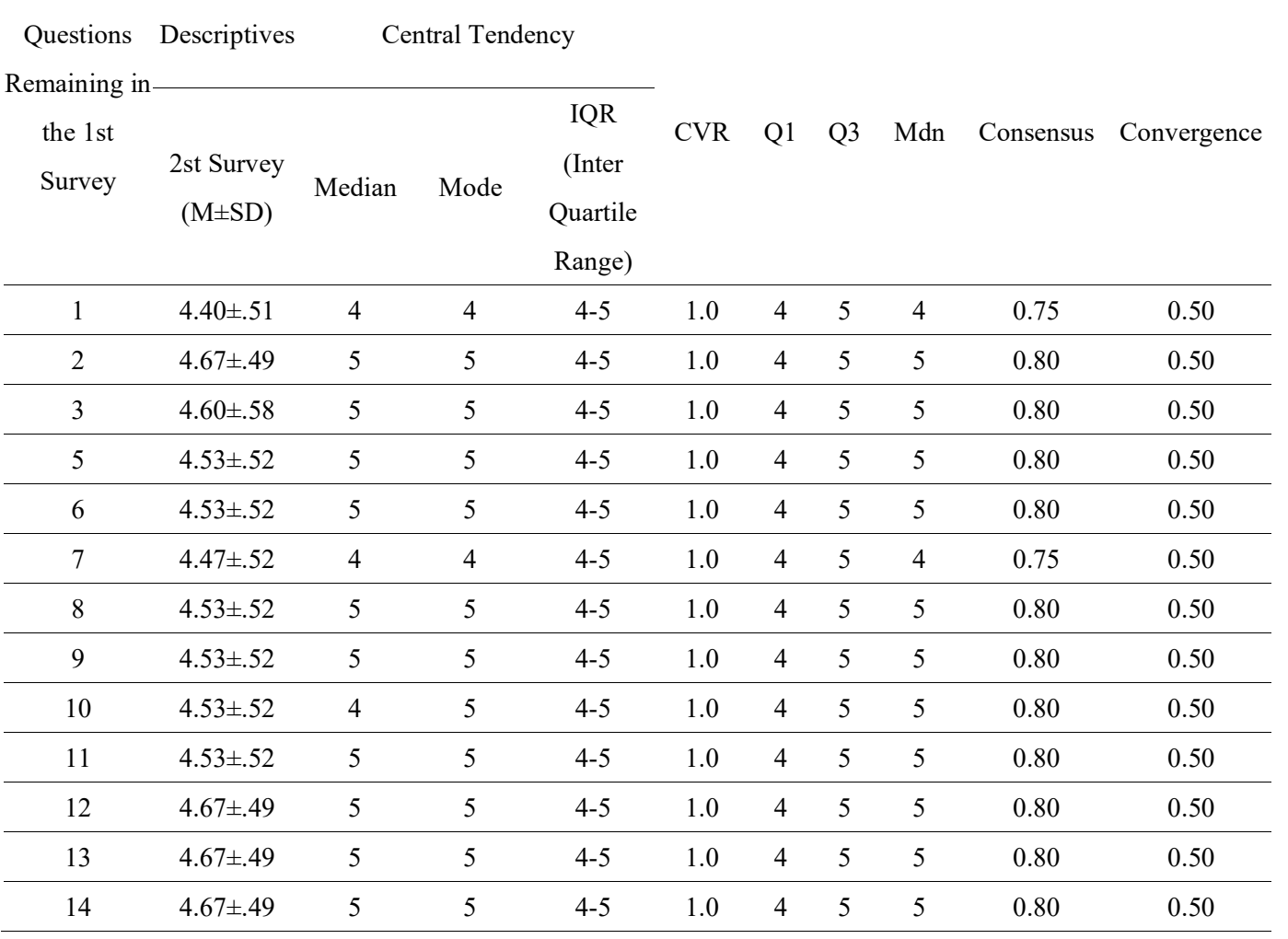

1. Frontal bone and Parietal bone 2. Frontal bone and Maxillar bone 3. Frontal bone and Sphenoid bone 5. Frontal bone and Zygomatic bone 6 . Parietal bone and Parietal bone 7. Parietal bone and Sphenoid bone 8 . Parietal bone and Temporal bone 9. Parietal bone and Occipital bone 10. Occipital bone and Temporal bone 11. Sphenoid bone and Temporal bone 12. Sphenoid bone and Zygomatic bone 13. Zygomatic bone and tenporal bone 14. Zygomatic bone and Maxillar bone

Table 6. Analysis of the validity of the assessment factors of the results of the Cranial Traction Therapy Program 


\begin{tabular}{|c|c|c|c|c|c|c|c|c|c|c|}
\hline Questions & Descriptives & & tral Tenc & ncy & & & & & & \\
\hline $\begin{array}{c}\text { Remaining in } \\
\text { the } 1 \text { st } \\
\text { Survey }\end{array}$ & $\begin{array}{l}\text { 3st Survey } \\
(\mathrm{M} \pm \mathrm{SD})\end{array}$ & Median & Mode & $\begin{array}{c}\text { IQR } \\
\text { (Inter } \\
\text { Quartile } \\
\text { Range) }\end{array}$ & CVR & Q1 & Q3 & Mdn & Consensus & Convergence \\
\hline 1 & $4.87 \pm .35$ & & & & & & & & & \\
\hline 2 & $4.87 \pm .35$ & & & & & & & & & \\
\hline 3 & $4.93 \pm .26$ & & & & & & & & & \\
\hline 5 & $4.93 \pm .26$ & & & & & & & & & \\
\hline 6 & $4.93 \pm .26$ & & & & & & & & & \\
\hline 7 & $4.93 \pm .26$ & & & & & & & & & \\
\hline 8 & $4.93 \pm .26$ & 5 & 5 & $5-5$ & 1.0 & 5 & 5 & 5 & 1.00 & 0.00 \\
\hline 9 & $4.87 \pm .35$ & & & & & & & & & \\
\hline 10 & $4.93 \pm .26$ & & & & & & & & & \\
\hline 11 & $4.93 \pm .26$ & & & & & & & & & \\
\hline 12 & $4.93 \pm .26$ & & & & & & & & & \\
\hline 13 & $4.93 \pm .26$ & & & & & & & & & \\
\hline 14 & $4.93 \pm .26$ & & & & & & & & & \\
\hline
\end{tabular}

1. Frontal bone and Parietal bone 2. Frontal bone and Maxillar bone 3. Frontal bone and Sphenoid bone 5. Frontal bone and Zygomatic bone 6. Parietal bone and Parietal bone 7. Parietal bone and Sphenoid bone 8. Parietal bone and Temporal bone 9. Parietal bone and Occipital bone 10. Occipital bone and Temporal bone 11. Sphenoid bone and Temporal bone 12. Sphenoid bone and Zygomatic bone 13. Zygomatic bone and tenporal bone 14. Zygomatic bone and Maxillar bone

Table 7. Analysis of the homogeneity (credibility) of the assessment factors of the results of the Cranial Traction Therapy Program

\begin{tabular}{cccc}
\hline Questions Remaining in the 1st Survey & 2st Survey (M \pm SD) & 3st Survey (M \pm SD) & $\rho$ \\
\hline 1. Frontal bone and Parietal bone & $4.40 \pm .51$ & $4.87 \pm .35$ & .756 \\
\hline 2. Frontal bone and Maxillar bone & $4.67 \pm .49$ & $4.87 \pm .35$ & .591 \\
\hline 3. Frontal bone and Sphenoid bone & $4.60 \pm .58$ & $4.93 \pm .26$ & .398 \\
\hline 5. Frontal bone and Zygomatic bone & $4.53 \pm .52$ & $4.93 \pm .26$ & .333 \\
\hline 6. Parietal bone and Parietal bone & $4.53 \pm .52$ & $4.93 \pm .26$ & .268 \\
\hline 7. Parietal bone and Sphenoid bone & $4.47 \pm .52$ & $4.93 \pm .26$ & .333 \\
\hline 8. Parietal bone and Temporal bone & $4.53 \pm .52$ & $4.93 \pm .26$ & .268 \\
\hline 9. Parietal bone and Occipital bone & $4.53 \pm .52$ & $4.87 \pm .35$ & .155 \\
\hline 10. Occipital bone and Temporal bone & $4.53 \pm .52$ & $4.93 \pm .26$ & .333 \\
\hline 11. Sphenoid bone and Temporal bone & $4.53 \pm .52$ & $4.93 \pm .26$ & .333 \\
\hline 12. Sphenoid bone and Zygomatic bone & $4.67 \pm .49$ & $4.93 \pm .26$ & .143 \\
\hline 13. Zygomatic bone and tenporal bone & $4.67 \pm .49$ & $4.93 \pm .26$ & .464 \\
\hline 14. Zygomatic bone and Maxillar bone & $4.67 \pm .49$ & $4.93 \pm .26$ & .464 \\
\hline
\end{tabular}




\section{Discussion}

As the suture lines of the cranial are small amounts of connective tissue interposed in between the bones, thereby connecting them, each parts of the cranial can be divided into their individual parts [44]. Through this division, this study established and categorized each items of cranial traction therapy as can be seen in Table 3 .

The treatment program of this study ultimately follows that in the book Cranial Osteopathy (Principles and Practice)by Torsten Liem[45], in that it performs traction at the parts that the book deemed as effective for correction therapy. These include the frontal bone spread technique involving the frontal bone part and the part where traction of the frontal bone and the parietal bone was performed in this study (item \#1); the cant hook technique involving the frontal bone part and the part where traction of the frontal bone and the maxilla was performed in this study (item \#2); the alternative technique involving the frontal bone part and the part where traction of the frontal bone and the sphenoid bone was performed in this study (item \#3); the frontozygomatic cant hook technique involving the part where traction of the frontal bone and the zygomatic bone was performed in this study (item \#5); the parietal spread technique involving the parietal bone part and the part where traction of the parietal bones was performed in this study (item \#6); the parietal technique involving the sphenoid bone part and the part where traction of the parietal bone and the sphenoid bone was performed in this study (item \#7); the lambdoid suture technique involving the temporal bone part and the part where traction of the parietal bone and the temporal bone was performed in this study (item \#8); the lambda technique involving the occipital bone part and the part where traction of the parietal bone and the occipital bone was performed in this study (item \#9); the occipitomastoid suture direct technique involving the occipital bone part and the part where traction of the occipital bone and the temporal bone was performed in this study (item \#10); the sphenosquamous pivot technique involving the sphenoid bone part and the part where traction of the sphenoid bone and the temporal bone was performed in this study (item \#11); the sphenozygomatic technique involving the zygomatic bone part and the part where traction of the sphenoid bone and the zygomatic bone was performed in this study (item \#12); the temporozygomatic bone technique involving the zygomatic bone part and the part where traction of the zygomatic bone and the temporal bone was performed in this study (item \#13); the zygomatic bone alternative technique involving the zygomatic bone part and the part where traction of the zygomatic bone and the maxilla was performed in this study (item \#14). The treatment program developed by this study will thus prove effective. 
The results of the precedent studies regarding items \#1-14 are as follows. The validity and the credibility of the development of this program was verified by an expert, and it was ascertained that all the items were effective in bringing about facial symmetry and are useful items to be applied in an alternative therapy. Also, the treatment points were chosen, as can be seen in Table 2, according to the stimulation methods for traction therapy. Item \#1 was the coronal suture part; item \#8 the squamous suture part; \#9 the lambdoid suture part; \#6 the sagittal suture part, at which three points were treated; items $\# 2, \# 3, \# 4, \# 5, \# 7, \# 10, \# 11, \# 12$, and \#13 were the sphenofrontal suture, the sphenoparietal suture, the occipitomastoid suture, and the sphenosquamous suture parts, and for those items one point was treated respectively.

In regards to the points of evaluation for stages 1,2 , and 3 of this cranial traction therapy program, in which its validity and homogeneity (credibility) were verified, $\# 4$ was deleted out of the 14 items after it did not meet the criteria of evaluation, and thus 13 items were evaluated. The figures representing the consensus regarding the development of this program can be seen in Table 3 . The categorization of each item in this study can be found in some manual treatment therapies of skin care that use similar methods as this one. However, there has never been an authorized care program that involves cranial traction therapy that is based on scientific analyses and data, as well as one that involves the correction of facial asymmetry through the former. The program will be used in the dental and medical world, as well as in some skin care academies and associations, to theorize the correction of facial asymmetry. It has validity and credibility as a program that can correct facial asymmetry by stimulating the suture parts of the cranial through traction therapy, and through its commercialization, it will contribute to the correction and prevention of facial deformities.

This study shows that it is possible to change the shape of the face by applying pressure to the cranial before getting correction for facial asymmetry. In cases where facial asymmetry has occurred due to one's environment after birth, it shows that if plagiocephaly (of the cranial's soft tissues) is treated by applying pressure to parts of the cranial, it is possible to prevent facial deformity or asymmetry that would have ensued otherwise, allowing one to retain a harmonious face shape.

\section{Conclusions}

The purpose of this study was to develop a cranial traction therapy program that will correct facial asymmetry. In order to do this, it utilized the cranial traction therapy that was suggested by a group of experts; and by testing its validity and credibility, a cranial traction therapy program that could be used to correct facial asymmetry was developed. The purpose 
of this study and alternative measures were provided as the study's baseline data. The program will have utility for improving facial asymmetry, and can be used as a supplementary therapy or a special care therapy to help achieve balance.

Author Contributions: Conxeptualization, K.-N.P.; Methodology, K.-N.P., J.H. and Y.P.; writion-original draft preparation, K.-N.P., J.H. and Y.P.; writion-review and editing, K.-N.P., J.H. and Y.P.; visualization, K.-N.P., J.H. and Y.P.; project administration, S.-Y.P. All authors have read and agreed to the published version of the manuscript.

Funding: This research received no external funding.

Acknowledgments: This study was supported by CHA University research grant.

Conflicts of Interest: The authors declare no conflicts of interest.

\section{References}

[1] Kim, M.J. Feelers, safe to receive from the medical staff who provide various options. Medicaltoday, 2020.08.11. URL: http://www.mdtoday.co.kr/mdtoday/index.html?no=395332

[2] Lee, J. K..; Jeong, I. W. Zygomatic Bone Reduction Surgery, Dental clinic. 2002, 7:876-880.

[3] We, S.Y. The effect of golgeun therapy on facial volume, thickness of cheekbone and mastication area. Doctoral dissertation. Seo kyeong University. Korea. 2012

[4] Han, S. H. An Effect and Satisfaction of Hand Shaping Massage on Facial Contraction. Masters thesis. Dan kook University. Korea. 2016

[5] Hinds EC.; Reid LC.; Burch RJ. Classification and management of mandibular asymmetry. American Journal of Surgery. 1960;100:825-34.

DOI: https://doi.org/10.1016/0002-9610(60)90513-4

[6] Ahn, J.S.; Hwang HS. Relationship between perception of facial asymmetry and posteroanterior cephalometric measurements. The Korean Journal of Orthodontics. 2001;31:489-498.

URL: http://www.dbpia.co.kr/journal/articleDetail?nodeId=NODE02104726

[7] Peck, H.; Peck, S. A concept of facial esthetics. Angle Orthod. 40: 284-318, 1970.

[8] Park, J.S. Evaluation of the Facial Soft Tissue in the Frontal View After Surgical Correction of Facial Asymmetry. Masters thesis. Yon sei University. Korea. 2007

[9] Shah, S. M.; Joshi, M. R. An assessment of asymmetry in the normal craniofacial complex. Angle. Orthod. 1978. 48: 141-148.

DOI: 10.1043 / 0003-3219 (1978) $048<0141:$ AAOAIT $>2.0 . C O ; 2$

[10] Peck, S.; Peck, L.; Kataja, M. Skeletal asymmetry in esthetically pleasing faces. Angle Orthod. 1991. 61:43-48. DOI: 10.1043/0003-3219(1991)061<0043:SAIEPF>2.0.CO;2

[11] Chebib and Chamma. Indices of craniofacial asymmetry. Angle. Orthod. 1981. 51: 214-226.

DOI : 10.1043 / 0003-3219 (1981) $051<0214:$ IOCA > 2.0.CO; 2 
[12] Williamson, E. H.; Varela, J. G. Correction of mandibular asymmetry with the ligated anterior repositioning splint. J. Craniomandib. Pract. 1990. 8: 30-4.

[13] Vig and Hewitt. Asymmetry of the Human facial skeleton. Angle. Orthod. 1975. 45(2): 125-129.

DOI : 10.1043 / 0003-3219 (1975) $045<0125$ : AOTHFS> 2.0.CO;

[14] Letzer, G. M.; Kronman, J. H. A posteroanterior cephalometric evaluation of craniofacial asymmetry. Angle. Orthod. 1967. 37: 205-211.

[15] Lee, J.Y. Soft tissue changes in relation to hard tissue changes of the facial asymmetry orthognathic surgery patients using a 3-Dimensional CT. Masters thesis, Yon sei University. Korea. 2008.

[16] Yogosawa F. Predicting soft tissue profile changes concurrent with orthodontic treatment. Angle Orthod. 1990. 60:199-206.

DOI: 10.1043/0003-3219(1990)060<0199:PSTPCC $>2.0 . C O ; 2$

[17] Lee, D.J. Comparison of asymmetric degree between maxillofacial hard and soft tissue in facial asymmetric subjects. Masters thesis. Won kwang university. Korea. 2009

[18] Park, H. K. Three-dimensional assessment of correlation between lip caning and craniofacial plane. Masters thesis. Yon sei University. Korea. 2013.

[19] Ferrario, V.F.; Sforza C.; Miani A.; Tartaglia G. Craniofacila morphometry by photographic evaluations. Am J Orthod Dentofacioal Orthop. 1993. 103:327-337.

DOI: 10.1016/0889-5406(93)70013-E.

[20] Haraguchi S.; Takada K.; Yasuda Y. Facial asymmetry in subjects with skeletal class III deformity. Anlgle Orthod. 2002. 72:28-35.

DOI: 10.1043/0003-3219(2002)072<0028:FAISWS>2.0.CO;2.

[21] Enlow,D.H. Postnatal Craniofacial Growth and Development, In Plastic Surgery Vol.IV.(ed.McCarthyJG). Philadelphia,WB SaundersCompany, pp.2497-2514, 1990.

[22] Ranly,D.M. Craniofacia Growth. Dent .Clin. North Am. 2000. 44:457-470.

[23] Lim,H.S. Influence of External Force to Cranial Bone in the Growth of Facal Bone in Growing Beagles. Masters thesis. A-jou Universit., Korea. 2005.

[24] Eileen L. DG.; Stanley S.; Dennis J. D. An Osteopathic Approach to Diagnosis and Treatment also viewed Paperback. 28 Oct. 2004

[25] Upledger, J, E.; Vredevogd, J, D. Craniosacral Therapy I Chixago: Eadtland Press. 1983.

[26] Kim,H.R. dialectical muscular science. Ansan: Cheongbi song, 2016.

[27] Kim,K.S. Cranial base shape according to skeletal maloccusion and effect of ceania base on maxilla and mandible. Masters thesis. Yon sei University. Korea. 2005.

[28] Park,S.J. Study on patients with facial asymmetry according to the skeletal pattern. Masters thesis. Yon sei University. Korea. 2006.

[29] You,E.j. A Study of Effect on Face Reduction and Physiological Factor of College Women by Nerve Stimulation Therapy. Masters thesis. Seoul Venture University. Korea. 2014. 
[30] Kwon,G.S. The Effect of Miso Facial Acupuncture on Facial Reduction and Improvement of Skin Condition. The Joumal of Koresn Acupuncture \& Moxibustion Medicine Sociene. 2012. 29(4): 7-18.

[31] Kwon,K.J. The Effects of Golgeun Therapy on Facial Size changes for Men in Their 20s and 30s. Masters thesis. Kon kuk University. Korea. 2012.

[32] Byun,I.H. Effect of Kyunggol Massage on Facial reduction. Masters thesis. Soong sil University. Korea. 2008.

[33] Kim,H.J. Analysis of Influence Factorsand Improvement Study of FacialAsymmetry. Doctoral dissertation. Kon kuk University. Korea. 2014.

[34] Adler, M.; Ziglio, E. Gazing into the oracle: The Delphi method and its application to social policy and public health. London, UK: Jessica Kingsley Publishers, 1996.

[35] Giannarou, L.; Zervas, E. Using Delphi technique to build consensus in practice, International Journal of Business Science and Applied Management. 2014. 9(2), 65-82.

[36] Kim,S.B. Improvement Planning Theory. Seoul: Parkyoungsa, 1983.

[37] Skulmoski, G.; Hartman, F.; Krahn, J. The Delphi method for graduate research. Journal of Information Technology Education: Research. 2007. 6(1), 1-21.

[38] Alain Gehin. Cranial osteopathic biomechanics,pathomechanics \& diagnostic for practitioners. Churchill Livingstone. 2007.

[39] Franklyn Sills. Craniosacral-Biodynamics. North Atlantic Books. 2001.

[40] Kim,H.R. Beauty docent Human Resources Development Association. Face Fitting, Daejeon: AHA\&DSL, 2017.

[41] Lawsh,C.H. A quantitative approach to content validity, personal psychology, 1975. 28(4). p.563-575

[42] Park,S.Y. A Delphi Study on English Speaking Performance Assessment for Middle School 1st Graders. Masters thesis. Korean national university of education. Korea. 2019

[43] Park,J.H.; Seong,T.J.; Hong,S..H., Effects of medical schools and standardized patients on clinical performances of medical students: A cross-classified analysis. Korean Society for Educational Evaluation. Vol.24 No.1 [2011]. 175-189

[44] Ahn,H.J.; Sin, Kyoung-Jin.; Kwon, J.S.; Do, H.J.; Choi, J.H.; Kim, C.Y. The Closure Stage of Cranial Sutures in Correlation with Age. Journal of Oral Medicine and Pain. 2001.Vol.26 No.4. 377-393.

[45] Torsten Liem. Cranial Osteopathy (Principles and Practice). Churchill Livingstone; 1st, 2005 